\title{
The Extent of Using of Information and Telecommunications Technology (ITT), by the Teachers of Social Studies in Tafila Governorate, and the Obstacles That Hinder Its Usage
}

\author{
Ruba al Mahasneh \\ Tafila Technical University, Tafila, Jordan \\ Email: mashhad33@gmail.com
}

How to cite this paper: al Mahasneh, R. (2017). The Extent of Using of Information and Telecommunications Technology (ITT), by the Teachers of Social Studies in Tafila Governorate, and the Obstacles That Hinder Its Usage. Creative Education, 8, 587606.

https://doi.org/10.4236/ce.2017.84046

Received: August 21, 2016

Accepted: April 22, 2017

Published: April 27, 2017

Copyright ( 2017 by author and Scientific Research Publishing Inc. This work is licensed under the Creative Commons Attribution International License (CC BY 4.0).

http://creativecommons.org/licenses/by/4.0/

\begin{abstract}
This study aimed at investigating the extent of using the applications of information and telecommunications technology (ITT), by the teachers of social studies in Tafila governorate, and obstacles that hinder such usage. To accomplish the goals of the study, an instrument was designed for data collection, verification of confidence and stability. The instrument was distributed over the sample of 129 male and female teachers, by a percentage of $84.7 \%$ of the study population. The most important results of the study were, that using applications of information and telecommunication technology by the teachers of social studies in the primary public schools was medium. The obstacles related to the equipment were high, while obstacles related to the technical and administrative aspect, beside the preparation of the teachers were medium. The study found no statistically significant differences at a $<0.05$ for using these applications attributed to gender, qualifications and experience of teachers. The researcher recommends the necessity for more efforts to enhance the using of these applications by the teachers of social studies more efficiently, through qualifying teachers to practice better the technological skills, in order to improve the performance of teachers.
\end{abstract}

\section{Keywords}

Information Technology, Teachers of Social Studies, Primary Grade

\section{Introduction}

The information technology is recognized as the symbol for advanced countries. 
Information technology is used widely in modern life to facilitate procedures, solve problems, besides the multiple applications in every aspect of life in accurate approaches and cost effective usage. Information technology saves money, time, and efforts in several fields of academic, manufacturing and management decisions.

Technology is a Greek term where techno means skill, profession; and logy means science or art, so technology means the art of skills which is related to the study of skills in a logical approach to execute a pre specified task (Karmah, 2010; Fisher \& Brown, 2006).

The definitions of information technology are varied where al salimi (2010) defined it as that modern science of practical forms and characteristics of information, including searching, organizing, formatting, collecting, and processing of data. Qandeelji (2010), defined it as the technology that integrates the computation systems with linkage via rapid telecom means, in order to transfer data, information, texts, figures, tables, image, audio, video and other applications.

Information is the outcome of data processing either manually or electronically or both, with a specific content and a high level of reliability. Information differs than data in that information provides the decision makers with opportunities to make decisions suitably, timely and accurately through the data analysis and outcomes. But such data remains abstracts and obscure inputs that we can't benefit without processing. Information is characterized with accuracy, simplicity, economy, modernity and logic, besides presenting it in the shortest time as well as verification ability and reliability (Zeighan \& Alkhateeb, 2009; AlKhatib, 2009; ALzaboon \& Ababneh, 2010; Grudin 1990; Gusnard, 2001).

The task of education improvement (teaching and learning) is one of the most critical priorities of the most advanced and developing countries. This is considered due to the belief that such process contributes actually to achieving the goals of these countries. Preparation and qualifying the teacher is one of the most important factors, that help in achieving the expected educational development, which leads to the development of society in all aspects. The proficient teacher is the one who is capable to achieve the goals of his/her society in education field effectively and efficiently (Othman, 2004).

The goal of education does not include the group of knowledge only, but has become the ability to access original sources and employ them in different aspects. With the advent of technological advance, especially in information technology-i.e., telecom, networks, and internet, the teacher has become capable of accessing the research centers linked to world wide web in short time without geographical borders (Khoza'a, Al hirish, \& Jawarneh, 2006).

The using of technology in educational and teaching process has become necessary to comply with the requirements of modern life. The technology has been changing the role of teacher and learner alike, where learner has become the central focus in learning while the teacher has become instructor, a guide and a facilitator for learning rather than previous roles of knowledge conveyor. The educational process has become participatory among teachers and learners (Helfer, 1997; Lieberman, 2005). 
The information technology and telecom provides several alternatives for learning, thus enabling learner to obtain self learning, feeding, and opportunity for developing the curricula textbooks, teaching techniques and multiple educational tools for saving information on multimedia (Ajir, 2004; Schnase \& Cunnius, 1995).

IT and telecom acquires its importance through goals that should be achieved, that is providing the vast potentials and capabilities of ITT to be reflected on the learner behavior and capabilities, with continuous follow up to secure the buildup of cognitive capabilities and maintain them (Akahori, 2002).

Therefore IT and Telecom perform a great role in enhancing the teacher to become proficient and achieve the goals, as well as increasing the return of education in less time and costs with increased quality. The IT and Telecom contribute to the display of information where it added several audiovisual templates, while the time of learning has become flexible based on the pace of learner. The assessment process has no longer been based on comparing the grades of students but their achievements of lesson objectives (Rawathiah et al., 2011).

The teaching situation that applies IT and Telecom has several advantages, such as:

Interaction of learners with technology and increases their creative capabilities.

Train the learners on higher skills of thinking and urge them to explore and conclude.

Let learners be accustomed to the rapid retrieving of informatics through controlling the teaching situation.

Enhance the motivation of learner towards learning when becoming in touch with results of his learning.

Assist teachers to select modern teaching approaches that use technology to improve the teaching process.

Take the individual differences among learners into account through variation of progress and experience presented.

Save effort, money and time (Packard \& Rais, 2003).

Eissan \& Ala'ni (2008) \& Cohn \& Geske (1990), indicate the importance of studying the actual performance of educational instructions and their potentials, in the light of transformation to the electronic environment. It is the ability to build a data base that can be accessed easily, to handle the administrative policies and approaches practiced, like planning, organizing communicating, decision making; while the phase of implementation to take the electronic network hierarchy form, in which all efforts are harmonized and integrated.

McAndrew et al. (2004) indicate the importance of learners participation in knowledge which leads them to peruse their learning, to sustain their professional growth within an environment that is capable to encounter challenges, and competition of surroundings events in an ever changing world. This environment encourages the collaborative learning or collective learning and exchanges experiences through information and live texts that are stored in the electronic network (McAndrew et al., 2004). 


\section{Problems and Questions of Study}

The results of different studies indicate the effectiveness and efficiency of using technology in learning and teaching process, such as, Judah (2004), Alhusari (2014), Khreishah (2011) who indicated the efficiency of using technology in learning and teaching.

Due to the need for developing progress dedicated for social studies teaching, to improve the interactive process of education, the educational institutions, including schools, seek to match the new and advanced technology to grasp the various aspects of knowledge. This technology has become a must in the teaching learning process for its vital results in improving the educational output through assisting teaching to handle the curriculum efficiently (Al Sharhan, 2002).

The researcher, through her educational practices, noticed a little usage of ITT in social studies teaching in the schools. Some teachers have been found with no knowledge in the ITT usage, despite the plans of the Ministry of Education to link the schools to the web, and train the teachers to get the required skills for teaching through ITT. Therefore the study will answer the following questions:

1) What is the degree of using ITT in teaching social studies for primary grades?

2) What are the obstacles that hinder the usage of ITT in teaching social studies for primary grades?

3) Are there statistically significant differences at a $<0.05$, in the usage of ITT, by teachers for primary grades, attributed to gender, qualification, and experience?

\section{Objectives of the Study}

The study aims at identifying the degree of ITT usage by the teachers of social studies for primary grades, determining the obstacles that hinder this usage by teachers, and recognizing whether there are statistically significant differences attributed to gender, qualification and experience of teacher.

\section{Importance of the Study}

The study gets its importance from the following:

Ministry of Education in Jordan is totally interested in education process, through improvement an development in continuous plan. It seeks to benefit the new technologies in the sustained and active education. It helds many conferences for this purpose and seeks all possible means to use these technologies in the educational system. The ministry applies the results of experiments and studies, and uses the feedback so all interested in the educational topics, academics and administrators can benefit such technology, especially the teachers (female and male) of social studies.

The determination of the ITT difficulties may provide efficient educational process a clear view about these difficulties, which in turn will contribute to taking procedures to overcome their obstacles and improve the process.

Lack of studies that investigate the use of technology by teaches of social stu- 
dies.

Higher levels of educational system can benefit from this study, to diagnose the usage of ITT by the teachers of social studies in the high schools of Tafila Governorate, and take the corrective actions.

Teachers, professionals and academics can benefit the teaching approach for social studies, through comprehension and application of IT accurately.

Responses to recommendation of research and studies about the usage of ITT.

Conceptual and procedural definition:

Information Technology:

It is a set of software and procedures related to the computer and Internet, represented by e-mail, written, audiovisual discussion, and virtual classes. The technology was measured by instrument developed by researchers (Philip, 1988; Banat, Ghaith, \& Badarin, 2013).

Primary grade:

It is the education grade (4th - 10th) grade.

Teachers of social studies:

They are the teachers who taught the social studies (society and nation), history, and geography, education (national and civil) in the academic year 2014/2015.

\section{Literature Review}

Many Arabic and none arabic studies were conducted on the topic of using ITT, by the teaching of social studies, and the obstacles that hinder their efforts. These studies handled the topic from one specific view point.

Based on the knowledge of the researcher, through her search in catalogues and other literary sources, there were no studies that discussed the usage of ITT by social studies teachers, and the obstacles against such usage.

ALmousa (2002) aimed at recognizing the use of information technology and computer in the Primary education, besides recognizing the difficulties that hinder the opportunity of using such technology in education. The sample consisted of 489 teachers in the Gulf state. The results indicated the capability of computer to increase and improve the level of academic achievements. It also indicated that computers courses were still in the beginning, despite its importance in the primary grade in all related countries. The study concluded that the most critical obstacles were ignoring training for teaching to use and benefit completion educational process beside the high cost of the computers.

Hinnawi (2003) study aimed at recognizing the attitude of academic supervisors towards the use of internet in education of Alqods Open University, Palestine. The researcher applied the descriptive methodology, where the study sample consisted of 360 male and female supervisors. The results of the study indicated that the attitude of supervisors towards using internet in education were positive, to a great level, for all directions and for the total score of these dimensions. The study also shared statistically significant differences among these attitudes, that were attributed to the academic program, rate of using internet, de- 
gree of user skills in internet, possession of computer besides statistically differences among these attitudes attributed to gender, position, qualification, age, and experiences.

Al Jund (2005) study aimed at investigating the efficiency of system units in developing the competencies of applying ITT, by the secondary grade teachers in Saudi Arabia, besides studying the present status of ITT in Saudi schools, and identifying the required competencies by female and male teachers at secondary schools.

The researcher used the experimental approach through a sample of $120 \mathrm{fe}$ male and male teachers. She applied the four modules of ITT concepts and fields of ITT, followed by achievement test about the learning content in these modules, as well as the questionnaire for secondary schools teachers. The results indicated a statistically significant impact for gender on the attitudes of teachers towards employing the IT impact for qualifications, experience and their interaction.

The study also revealed the efficiency of modules in developing the competencies of teachers in using ITT, where there were statistically significant differences between the results of prior and posterior achievement test, while there were no statistically significant differences among the female and male teachers in performance for the same instrument.

Alshiri (2005) Study aimed at identifying the techniques and applications of (ITT), used by the teachers of secondary private schools in Riyadh, Saudi Arabia. The researcher applied a questionnaire on 81 female and male teachers. The researcher used descriptive and analytic approach. The results of the study indicated that the rate of using ITT by teachers was low in general. The study revealed the needs of teachers for the teaching skills that are related to ITT applications in teaching-learning process. The study concluded that a mechanism should be established to set comprehensive plans for the long range for employing and using ITT in education.

McCoy (2005) recognized the using of computers by teachers and counselors on jobs, and their feeling of acquaintances and confidence while using the skills of computers. The sample consisted of 222 counselors. The results indicated that the feeling of confidence while using computer differed according to the different activities implemented. They felt more confident and acquainted when using word processor followed by the design of Internet sites. They used the word processor far more than any other skills. The results indicated that counselors used computers to write letters, reports, lists of students, save this information and retrieve it. The results indicated that less than half of the sample used computer in group or collective, personal and social, counselling. The results showed that counselors didn't use the email service in communicating with parents, students and colleagues.

Alghamedi (2005) aimed at determining the present use of computers at work by school counselors besides revealing the factors and difficulties affecting such use. The sample consisted of 126 counselors at the secondary schools in Riyadh, Saudi Arabia. The results showed more positive attitudes towards the use of 
computer at work, besides, that there was statistically significant relationship between frequent use of computers by counselors and the degree of their perception to its benefit. The results also indicated no statistically significant differences in using computer skills attributed to age and experience; results also showed that qualified teachers for counseling were better in using computers than the unqualified teachers. The most critical difficulties were the lack of training in computer or necessary skills.

Walton \& Lenda (2006) aimed at establishing an executive perception for ITT skills and proficiencies by teachers of Chicago schools, according to the international standards. The study used the descriptive approach, through applying an instrument, which consisted of nine dimensions. The study concluded that 51\% of Chicago school teachers were ready to implement the skills and proficiencies according to international standards. It also revealed that there was a serious low level of the HTML and Page design on web among 9 dimensions. The study found no statistically significant differences attributed to gender. It also indicated that $81 \%$ of the sample requested on job official training to meet the international standards.

Steven (2007) aimed at recognizing the impact of training teachers of special education, through Internet, on teaching the societal skill. The sample consisted of 25 teachers, who faced many difficult behaviors, at low and medium level, that can hinder the educational process. These behaviors of students included anger, crying, shouting, fear and tear out the educational materials or sadness. These symptoms are common among the students with emotional or behavioral disorder or learning and intellectual disabilities. The training was conducted during class sessions on Internet, through which teachers received training during 60 sessions. The results indicated that the rates of response were high, where 16 teacher benefited from the sessions and enhance their professional proficiency.

Alomari and Alomari (2008) aimed at recognizing the applying off ITT in the skills of class teaching situation in the $1-3$ grades as perceived by the teachers; and the constraints against the usage. The sample consisted of 310 female and male teachers of $1-3$ grades at the schools of Irbid, Jordan. The results indicated that 31 of 55 schools investigated used ITT, while $26 \%$ of teachers used computer and Internet in planning the classes, and $21 \%$ of them used it for assessment, where $15 \%$ used it to implement the lessons. The tests and class administration items obtained the lowest scores of use by $5 \%$ and $2 \%$ respectively, while the personal uses were $21 \%$ of usage. The results indicated the most crucial constraints were the unsatisfaction of headmasters with change besides unsuitable class environment for applying ITT.

ALdhoon, Maamoon (2008) study aimed at investigating the use of e-learning system as perceived by teachers of Irbid governments. To accomplish the goals of the study, the researcher developed an instrument to measure the degree of possession and use of e-Learning system by sample members, besides the obstacles they encountered. The results indicated that the degree of e-learning skills by teachers was medium, while the degree of using such system was low. The 
sample members indicated the possibility to benefits such e-learning system by high degree, despite the obstacles they faced.

Rogers (2008) study aimed at evaluating the communication process among teachers and parents, in the intermediate school, through using the different multimedia as email and the website of the school. The sample consisted of 162 parents and 64 teachers. The data was collected by conducting interviews between the evaluation team and sample members. The results indicated that $35.8 \%$ of parents used email to communicate with teachers while $50 \%$ of them used the school website to arrange for appointments. The results also found that $55.6 \%$ of parents used the website to follow up the homework of their sons, while $42.6 \%$ communicated by phone with the teachers. The results showed that $95.8 \%$ of teachers used email to communicate with parents to inform them on reports, scores and behaviors of their kids. The results indicated that $45.5 \%$ of teachers used the school website to send the homework to students. The results underlined some the obstacles that hindered parents from using email to communicate with teachers like slow Internet and lack of skills to use ITT.

Stasious and Angali (2008) aimed at evaluating the use of ITT in education process. The researchers conducted a survey of the psychological characteristics and the factors affecting the use of ITT. The sample consisted of 587 teachers and principals at the public schools in Cyprus. The researchers applied a questionnaire, that consisted of several dimensions, to measure the level of using ITT and skills of teachers and principals, beside recognizing their attitude towards ITT. The results indicated no statistically significant positive relationship between the use of ITT and the attitude of teachers and principals.

Alhazzani (2008) aimed at identifying the use of computer and IT in the secondary schools in Riyadh-Saudi Arabia as perceived by female teachers and their students. The researchers applied the questionnaire, to collect data from $78 \mathrm{fe}-$ male teachers and students. The researcher adopted the descriptive-analytical approach, where results showed that the highest percentage to use IT and computer by teacher was presented, by developing the knowledge of teachers in their specialization, through Internet by $94 \%$. All teachers indicated that there was no communication with parents by email. The study recommended that Internet should be spread over schools through high-speed cables besides providing computers.

Alattal (2009) study aimed at investigating the use of e-learning system, by female and male teachers of Amman second directorate of education-Jordan, and their attitudes towards e-learning. The sample was selected through simple random sampling. The researcher developed a questionnaire to achieve the goal of the study. The sample consisted of 459 female and male teachers. The results indicated that the level of using e-learning by teachers was medium, while they used e-learning almost for data entry and save scores of students on the net in order to use it for promoting students to higher grades and review the information of students. The lowest scores were from items related to communication with students and parents by email. That is all showed positive attitudes toward 
the use of e-learning in medium level, besides that there were obstacles that hindered such use like the large volume of curriculum and teaching duties as well as the large number of students and classes and the lack of high speed communication.

Hathanwi (2009) aimed at recognizing the role of informatics in developing the vocational performance of teachers at vocational schools in Palestine as perceived by principals and vocational teachers. The sample consisted of 188 principals and vocational teachers, where the researchers used the descriptive-analytical approach and questionnaire of three dimensions, knowledge resources, software and equipment. The results indicated the lack of specialized technical training programs for teachers where these programs have the largest role in using information at schools while informatics has the largest role in developing the performance of vocational of teachers.

Albalawi (2010) aimed at recognizing the obstacles against using technology in education as perceived by the teachers of Arabic language at public schools in Tabuk-Saudi Arabia. The sample consisted of 150 teachers. To achieve the goals of the study the researcher applied a questionnaire. The results indicated that obstacles as perceived by Arabic language teachers were medium while there were no statistically significant differences in the teachers estimation of obstacles they face attributed to qualifications, educational experience and grade.

Almekhlafi (2011) aimed at measuring the efficiency of a computer program and developing the skills of ITT by students at university of Ta'az-Yemen, and measuring it's impact on their attitudes toward self learning. The program was applied on the sample which consisted of two groups of students; experimental and control. The researcher applied achievement tests, observation cards and measure of student's attitudes toward self learning as instruments. The results indicated inefficiency of the computerized program in developing the attitudes of students towards the self learning.

Banat et al. (2013) study aimed at identifying the degree of using computer technology by teachers of social studies at public schools, through building a measure by them, then applying the measure on a sample of 166 female and male school counselors working for public schools in seven directorates of education. The results indicated that social studies teachers used computer technology by medium level, while they have medium positive attitude towards computer technology. The results indicated no statistically significant differences $(a \leq 0.05)$ towards using computer technology attributed to gender, type of school, number of students and computer courses. The results indicated statistically significant differences attributed to the qualifications for that favor of bachelor degree holders, years of experience for the favor of teachers with less than five years.

\section{Comments on Literature Review}

Through the literature review, our study will benefit the procedure and results of these studies. despite that know study has combined both the use off ITT by social studies teachers and obstacles. 
Objective: Most previous studies aimed at investigating the impacts of IT on another valuable, also studies that handled the obstacles that hinder such use.

Samples: The sample varied according to the targeted segment and number. In general most sample members were persons working for educational institutions such as teachers and principals.

Instruments: most studies used questionnaires as instruments for data collection.

Our Study was similar to the previous studies in investigating the concepts of technology use and obstacles. It also used the questionnaire as an instrument for data collection. But this study differed in that it focused on:

Place of population: it was teachers of social studies in public school at the Tafila, Jordan.

The goal: this study aimed at determining the use of technology by the teachers of social studies as they pereceived and the obstacles that hindered their use. Upon the knowledge of the researchers there was no similar study for the same place and population.

\section{Population and Sample of the Study}

The population consisted of all female and male teachers of social studies at primary public schools of Tafila, Jordan by 129 teachers according to the statistical information of education Ministry for academic year 2014/2015 (Table 1). The sample consisted all those teachers.

\section{Study Instruments}

Based on the literature review and previous studies related the applying of IT in teaching, such as Hithnawi (2009), Alghamedi (2005) and McCoy (2005), the researcher developed the study instrument (the questionnaire), which consisted of three parts as follows:

The first part consisted of the title and goal of the study, as well as the data about the sample members, and variables.

The second part consisted of two sections as follows:

The first section included 13 items that represented the level of applying ITT, by the teachers of social studies for primary grade, in the schools of Tafila City.

The second section included 23 items that reflected the obstacles against applying ITT in three dimensions as follows:

Table 1. Distribution of samples according to valuables.

\begin{tabular}{cccc}
\hline Variable & Type & No. & Total \\
\hline \multirow{2}{*}{ Gender } & Male & 53 & 129 \\
& Female & 76 & \\
Qualifications & Bachelor & 106 & 129 \\
& Graduate & 23 & \\
Experience & $1-5$ & 44 & \\
& $6-10$ & 46 & 129 \\
& $>10$ & 39 & \\
\hline
\end{tabular}


2.2.1 Obstacles that were related to the preparation of teachers and included five items.

2.2.2 technical and administrative obstacles that included eight items.

2.2.3 Obstacles related to devices and supplies that included ten items

The instruments used the 5-point likert Scale. The values of arithmetic means manipulated by the study to explain the results are shown in Table 2.

\section{Confidence of Instrument}

To verify the validity of instrument contents it was submitted to a group of reviewres, who were academic specialists in the Jordanian universities and the teachers of social studies at the Ministry of Education. The reviewers were asked to assess and appreciate the instrument in a whole, and write down their suggestions and notes, in terms of cohesion of items with the dimensions, the lingual consistency of items and their matching to the Jordanian environment.

The reviewers indicated that the questionnaire items were consistent to measure the dependent variables. They approved the suitable items, while they recommended some modifications for other items. At least $85 \%$ of reviewers agreed upon the appropriate items, where the researcher conducted the required modifications, through deletion and addition, so as to be compatible with the recommendations of reviewers. The researcher formulated the last version of questionnaire, thus the second part included 18 items while the third section included 23 items.

\section{Stability of Instrument}

The instrument was applied on 16 members of the population, and then the researcher calculated that Chronbach-Alpha coefficient as shown in Table 3 for coefficients of suitability.

The table shows that the values of stability coefficients were accepted for study purposes.

\section{Variables of the Study:}

1) Independent Variables:

Table 2. Test of study.

\begin{tabular}{ccc}
\hline Low degree & Middle degree & High degree \\
\hline$<2.33 / 5$ & $2.33-3.67 / 5$ & $>3.68 / 5$
\end{tabular}

Table 3. Values of stability coefficients.

\begin{tabular}{ccc}
\hline Instrument & Dimension & Stability coefficient \\
\hline $\begin{array}{c}\text { Use of ITT application } \\
\text { Obstacles against the use of } \\
\text { ITT application }\end{array}$ & Obstacles related to teachers & 0.85 \\
& Obstacles (technical and administrative) & 0.88 \\
& Obstacles related to materials and equipment & 0.79 \\
& Total & 0.87
\end{tabular}


Gender (male, Female)

Years of experience $(<5,6-10,>10)$

Qualifications (Bachelor, Graduate)

2) Dependent Variables:

The performance of dimensions measured by the instrument for this purpose, i.e.: Applying technology and obstacles that hinder its use

\section{Statistical Processing:}

The researcher applied SPSS to make the statistical processing as follows:

1) Frequencies, percentiles to describe the characteristics of population.

2) To answer questions 1 and 2 the researcher calculated arithmetic means and standard deviations.

3) To answer question 3 the researcher applied the Three-Way_ANOVA

4) To verify the stability of instrument the researcher applied Characteristic Coefficient.

\section{Display of Results:}

1) Results of question 1: What is the degree of ITT use by the teaches of social sciences for primary state?

To answer this question, the researcher calculated the arithmetic means and standard deviation for the performance of sample members for each item and for the instrument as a whole. Table 4 shows the results.

Table 4. Arithmetic means and standard deviations for the degree of applying the technology by the teachers of social studies in the primary grade for each item alone and for the instrument as a whole.

\begin{tabular}{|c|c|c|c|c|c|}
\hline Item No & Item content & Mean & St. Dev & Rank & Score \\
\hline 11 & I use YouTube to access educational videos & 3.60 & 1.44 & 1 & Med \\
\hline 12 & I use social media (Facebook, Twitter, Skype...) & 3.58 & 1.49 & 2 & Med \\
\hline 10 & I use e-books, e-Journals and e-Magazines & 3.54 & 1.42 & 3 & Med \\
\hline 1 & I use email to send and receive messages & 3.54 & 1.24 & 3 & Med \\
\hline 3 & I use Data show for presenting educational programs to students & 3.48 & 1.34 & 4 & Med \\
\hline 2 & I use websites and e-forums for educational purposes & 3.47 & 1.29 & 5 & Med \\
\hline 18 & I use Skype to hold video conference & 3.46 & 1.41 & 6 & Med \\
\hline 4 & I use Photoshop and Paint to produce bulletins and stickers for educational purposes & 3.46 & 1.39 & 6 & Med \\
\hline 13 & I use CD’s & 3.44 & 1.35 & 7 & Med \\
\hline 15 & I use Photoshop for image processing and animation & 3.41 & 1.39 & 8 & Med \\
\hline 17 & I use Multimedia software like Autherware and Director & 3.40 & 1.33 & 9 & Med \\
\hline 16 & I use dedicated software to learn creative skills like Design & 3.37 & 1.38 & 10 & Med \\
\hline 14 & I use Microsoft Office for educational purposes & 3.33 & 1.44 & 11 & Med \\
\hline 9 & I use audio Conferences by internet and mobile & 3.31 & 1.45 & 12 & Med \\
\hline 5 & I use Computer to design the educational applied registers & 3.13 & 1.36 & 13 & Med \\
\hline 7 & I use smart board & 3.01 & 1.38 & 14 & Med \\
\hline 6 & I use computer to design a comprehensive database about student & 2.96 & 1.25 & 15 & Med \\
\hline \multirow[t]{2}{*}{8} & I use voice mail & 2.82 & 1.35 & 16 & Med \\
\hline & Total & 3.35 & 0.97 & & Med \\
\hline
\end{tabular}


Table 4 shows that all items obtained medium degree, in the light of responses of sample members upon the criterion. It shows that item 11 (I use Youtube site to access the educational films in order to advise the students), obtained the highest rank, with a mean of 3.6 and standard deviation of 1.44. Item 8: (I use the VoiceMail), obtained the least rank with a mean of 2.82 and standard deviation of 1.35. The total estimation, for the degree of using technology by the teachers of social studies in Tafila primary schools, was medium with a mean of 3.35 and standard deviation of 0.97 .

\section{Results of Question 2:}

What are the obstacles that hinder the use of technology by the teachers of social studies for primary grade in Tafila schools?

To answer this question, the researcher calculated the arithmetic means and standard deviations of the estimation degree by sample members, for obstacles, that hinder the use of technology by the teachers of social studies for primary grade in Tafila schools, in terms of each dimension and the instrument as a whole, as shown in Table 5.

Table 5 shows that arithmetic means for the estimation degree, by the teachers of social studies in Tafila primary schools towards the obstacles that hindered using the technology, ranged between 3.35 - 3.68, while Standard deviations ranged between 0.79 - 1.22. The third dimension: (Obstacles related to devices and supplies) obtained the highest rank, with a mean of 3.68 and standard deviation of 1.02. The second dimension: (Technical and administrative obstacles) obtained the second rank, with a mean of 3.54 and standard deviation of 0.79 . The first dimension: (Obstacles related to the preparing of the teacher), obtained the least rank, with a mean of 3.35 and standard deviation of 1.22. The total estimation, for the degree of using technology by the teachers of social studies in Tafila primary schools, was medium with a mean of 3.56 and standard deviation of 0.86 .

Results of the Second Question: What are the obstacles that hinder the use of IT by the teachers of Social studies for the primary grade in the schools of Tafila?

To answer this question, the researcher calculated the arithmetic means and standard deviations of the estimation degree, by sample members, for obstacles that hinder the use of technology, by the teachers of social studies for primary grade in Tafila schools, in terms of the first dimension: (Obstacles related to the

Table 5. Arithmetic means and standard deviations of the estimation degree by sample members for obstacles that hinder the use of technology by the teachers of social studies for primary grade in Tafila schools in terms of each dimension and the instrument as a whole.

\begin{tabular}{cccccccc}
\hline \multirow{2}{*}{ Dim No } & Obstacles & \multicolumn{3}{c}{ No/items } & \multicolumn{3}{c}{ Standard } \\
& & per dim & Mean & Dev & Rank & Degree \\
\hline 3 & Obstacles Related to devices and supplies & 10 & 3.68 & 1.02 & 1 & high \\
2 & Technical and Administrative Obstacles & 8 & 3.54 & 0.79 & 2 & Med \\
1 & Obstacles related to the teacher and preparing & 5 & 3.35 & 1.22 & 3 & Med \\
& & & 3.56 & 0.86 & & Med \\
\hline
\end{tabular}


preparing of teachers), and the instrument as a whole, as shown in Table 6.

Table 6 shows that all items of the first dimension; (Obstacles related to preparing teachers), obtained medium degree in the light of responses of sample members upon the criteria. It shows that item 5 (There is much routine work that teachers are required to do), obtained the highest rank, with a mean of 3.39 and standard deviation of 1.16. Item 2: (Lack of material and moral incentives to the teachers applying information technology), obtained the least rank, with a mean of 3.32 and standard deviation of 1.21. The total estimation, for these obstacles, was medium with a mean of 3.35 and standard deviation of 1.22.

Table 7 shows that all items of the second dimension; (Technical and Administrative Obstacles), obtained medium degree, in the light of responses of sample members upon the criteria. It shows that item 9 (Unsuitable classrooms for technological devices), obtained the highest rank, with a mean of 3.58 and standard deviation of 1.27. Item 10: (Excess number of students subject to advice in classrooms), obtained the least rank, with a mean of 3.350 and standard deviation of 1.43. The total estimation, for these obstacles was medium with a mean of 3.54 and standard deviation of 0.79 .

Table 8 shows that all items of the third dimension; (Obstacles related to devices and supplies), obtained high degree in the light of responses of sample members upon the criteria, where the total mean was 3.68 and standard deviation was 1.02 .

Table 6. Arithmetic means and standard deviations of the estimation degree by sample members for obstacles that hinder the use of technology by the teachers of social studies for primary grade in Tafila schools, in terms of the first dimension: (obstacles related to the preparing of teachers), and the instrument as a whole.

\begin{tabular}{|c|c|c|c|c|c|}
\hline Item No & Item Content & \multicolumn{4}{|c|}{ Mean Standard Dev Rank Estimation Degree } \\
\hline 5 & There is much routine work that teachers are required to do & 3.39 & 1.16 & 1 & med \\
\hline 1 & Weak efficiency of using technological devices & 3.37 & 1.22 & 2 & Med \\
\hline 3 & Unsatisfaction of the benefits and values of technological activities & 3.34 & 1.2 & 3 & Med \\
\hline 4 & Weak english language proficiency of teachers hinders their use of technology & 3.33 & 1.32 & 4 & Med \\
\hline 2 & Lack of material and moral incentives to the teachers applying information technology & 3.32 & 1.21 & 5 & Med \\
\hline & Total & & 3.35 & 1.22 & med \\
\hline
\end{tabular}

Table 7. Means and standard deviations for the estimation degree, by sample members, of the second dimension: (technical and administration obstacles), that hinder their use of technology.

\begin{tabular}{|c|c|c|c|c|c|}
\hline Item No & Item Content & Mean & Standard Dev & Rank & Estimation Degree \\
\hline 9 & Unsuitable classrooms for technological devices & 3.58 & 1.27 & 1 & Med \\
\hline 7 & Lack of allocated budget by administration for using technology & 3.57 & 1.12 & 2 & Med \\
\hline 12 & Weak skills of students to use technology & 3.56 & 1.15 & 3 & Med \\
\hline 11 & Discouragement of administration for using technology & 3.55 & 1.41 & 4 & Med \\
\hline 13 & Lack of computerized educational programs in schools & 3.53 & 1.52 & 5 & Med \\
\hline 6 & Unavailable materials and technical devices in schools & 3.52 & 1.23 & 6 & Med \\
\hline 8 & Cautious of damaging technological devices while using by students & 3.51 & 1.34 & 7 & Med \\
\hline \multirow[t]{2}{*}{10} & Excess number of students subject to advice in classrooms & 3.5 & 1.43 & 8 & med \\
\hline & Total & 3.54 & 0.79 & & med \\
\hline
\end{tabular}


Table 8. Means and standard deviations for estimation degree, by sample members, of the third dimension: (obstacles related to materials and devices), that hinder their use of technology.

\begin{tabular}{|c|c|c|c|c|c|}
\hline \multirow{2}{*}{$\frac{\text { Item No }}{22}$} & \multirow{2}{*}{$\begin{array}{l}\text { Item Content } \\
\text { Lack of allocated budget for supporting the computer aided educational programs }\end{array}$} & \multicolumn{4}{|c|}{ Mean Standard Dev Rank Estimation Degree } \\
\hline & & 3.78 & 1.44 & 1 & high \\
\hline 15 & Lack of equipments for the halls dedicated to the teaching process & 3.77 & 1.32 & 2 & high \\
\hline 20 & Waste of time during moving to labs equiped for applying technology & 3.76 & 1.28 & 3 & High \\
\hline 17 & Slow internet and frequent faults of network in the schools & 3.67 & 1.3 & 4 & Med \\
\hline 19 & High cost of educational software & 3.66 & 1.19 & 5 & Med \\
\hline 18 & Lack of safety tools to use IT & 3.65 & 1.37 & 6 & Med \\
\hline 16 & Equipments and tools need frequent maintenance & 3.64 & 1.32 & 7 & Med \\
\hline 14 & Lack of technicians to supervise and maintain the labs & 3.63 & 1.36 & 8 & Med \\
\hline 21 & Classroom environment is not suitable for using technology during the teaching process & 3.62 & 1.26 & 9 & Med \\
\hline \multirow[t]{2}{*}{23} & Lack of computers & 3.61 & 1.33 & 10 & Med \\
\hline & Total & 3.68 & 1.02 & & high \\
\hline
\end{tabular}

Items 20, 15 and 22 indicated a high degree of estimation:

Item 22: (Lack of allocated budget for supporting the computer aided educational programs), obtained a mean of 3.78 and a standard deviation of 1.44

Item 15: (Lack of equipments for the halls dedicated for the teaching process), obtained a mean of 3.77 and a standard deviation of 1.32

Item 20: (Waste of time during moving to labs equiped for applying technology), obtained a mean of 3.76 and a standard deviation of 1.28

Items $(23,21,14,16,18,19$ and 17) obtained medium degree of estimation.

Item 17: (Slow of internet and frequent faults of network in the schools), obtained a mean of 3.67 and a standard deviation of 1.30

Item 19: (High cost of educational software), obtained a mean of 3.66 and a standard eviation of 1.19

Item 18: (Lack of safety tools to use IT), obtained a mean of 3.65 and a standard deviation of 1.37

Item 16: (Equipments and tools need frequent repair), obtained a mean of 3.64 and standard deviation of 1.32

Item 14: (Lack of technicians to supervise and maintain the labs), obtained a mean of 3.63 and a standard deviation of 1.36

Item 21: (Classroom environment is not suitable for using technology during the teaching process), obtained a mean of 3.62 and a standard deviation of 1.26

Item 23: (Lack of computers), obtained a mean of 3.61 and a standard deviation of 1.33

Question Three: Are there statistically significant differences $(a \leq 0.05)$, for using IT by the teachers of social studies, for the primary grade, attributed to gender, qualifications and experience?

To answer this question the researcher calculated the arithmetic means and standard deviations, for the degree of using IT by the teachers of social studies, for the primary grade in Tafila schools, according to the variables of the study, as shown in Table 9. 
Results of Table 9 show that there were apparent differences between the means and standard deviations, for the degree of using IT by the teachers of social studies, for primary grade in Tafila schools, according to the variables of the study. To recognize the significance of these differences among the arithmetic means, the researcher applied Three-Way_ANOVA, as shown in Table 10.

Table 10 shows no statistically significant differences in the values of means, for using ITT by the teaches of social studies for primary grade, in public schools of Tafila, attributed to gender, where $\mathrm{F}=0.563$ at significance level of 0.454 . There were no statistically significant differences attributed to qualification where $\mathrm{F}=1.88$ and significance level $=0.265$. There were also no statistically significant difference attributed to the experience, where $\mathrm{F}=1.561$ and significance level $=0.293$.

\section{Discussion of Results}

Discussion of results related to question 1: "what are the use of ITT by teachers of social studies of primary grade of public schools in Tafila?"

The results indicated that all items obtained a medium degree, which means that the teachers have skills and competency to handle the technological issues for their job. These skills and competencies help the teachers to use internet sites, like YouTube to access the educational films for student counseling, access the social media, use of libraries (books, journals and magazines), use of email to receive and send massage from and to students besides using data show to display the educational progress as well as accessing the electronic sites and forums to

Table 9. Arithmetic means and standard deviations for the degree of using IT by the teachers of social studies for primary grade in Tafila schools according to the variables of the study.

\begin{tabular}{cccc}
\hline Variable & Type & Mean & Standard Deviation \\
\hline \multirow{2}{*}{ Gender } & Male & 3.27 & 0.96 \\
& Female & 3.4 & 0.98 \\
\multirow{2}{*}{ Qualification } & Bachelor & 3.41 & 0.93 \\
& Graduate & 3.14 & 1.08 \\
\multirow{2}{*}{ Experience (years) } & $1 \mathrm{y}-5$ & 3.29 & 1.06 \\
& $6 y-10$ & 3.38 & 0.91 \\
& $>10$ & 3.4 & 0.91 \\
\hline
\end{tabular}

Table 10. Results of Three-Way_NOVA for impact of gender experience and qualification on using IT by the teaching of social studies.

\begin{tabular}{cccccc}
\hline Source of variance & Sig level & F. value & Mean average & Deg. Of freedom & Sum of squares \\
\hline Gender & 0.454 & 0.563 & 0.416 & 1 & 0.416 \\
Qualification & 0.265 & 1.88 & 0.086 & 1 & 0.086 \\
Experience & 0.293 & 1.561 & 0.751 & 2 & 1.502 \\
Error & ------ & ------ & 1.061 & 124 & 131.634 \\
& - & ---------- & -------- & 128 & 146.655 \\
\hline
\end{tabular}


benefit them in education.

These results are attributed to the possession of skills and competencies, resulting from qualifying and training programs, such as comprehensive computer training programs and ICDL course. These results are also attributed to the changing role of the teacher, from the traditional (paper and pen) to electronic (computer, networks, and internet). Such change occurred as a reflection for the development of educational studies, to enable teachers accomplish the expectations of their roles, as educators who take into account all educational dimension of education process, and who are able to use all technological means, to enhance their performance and accomplish the goals of educational system. It is possible that the medium degree of using ITT by social studies teachers may be attributed to the nature of teacher profession, where they focus on social and emotional factors, to modify the behavior of student and affect their attitudes, and not the transfer of information to students only (Alhaqiqah Aldawliah Liddirasat (Alhaqiqa for Studies), 2009).

Discussion of obstacles that hinder the use of technology by teachers of social studies for primary grade at public schools at Tafila.

Results indicated that, obstacles related to the equipment and materials obtained the first rank, with a mean of 3.68, while the least rank was for the obstacles related to the teacher and his/her preparedness, with a mean of 3.35. The total degree for these obstacles was medium with a mean of 3.56. Such results might be attributed to the newly-known concept of ITT in the public schools in Jordan, as well as newly applied technologies. Any new concept application requires providing equipments and material to spread it throughout schools with the necessary qualified human resources, strategic plans and comprehensive Databases. Results are also attributed to the care of education ministry to utilize all sciences and knowledge to serve the educational process. Therefore it is very vital to intensify the training and development programs and seminars to enhance the performance of teachers.

Discussion of the results related to question 3:

"Are there statistically significant difference, at a $<0.05$, for using technology by teachers of social studies, attributed to the variables of gender, qualification and experience?"

Results indicate no statistically significant differences at a $<0.05$ in using technology by teachers attributed to gender experience and qualifications.

This might be attributed to that the tasks performed by the female and male teachers are the same, such as interacting with students, offering educational services, both genders work under the same legal and social conditions. In terms of experience, the results indicated that the teachers at the beginning of their careers are active, enthusiast in doing their tasks so as to secure their permanent employment, while they ask for training programs to improve their performance. They adopt the technology to get distinguished from other teachers and to improve the educational process. In relevance to qualification, all teachers are keen to apply the most effective approaches in teaching, especially the ministry 
of education may assign duties to teachers differ than their specializations, so teachers will accept the challenge to overcome all obstacles, so as to develop and improve the educational process.

\section{Recommendation}

The researcher recommends the following:

1) It is necessary to prepare programs that show clearly the education tasks of teachers, including teaching and counseling, which can help them conduct their duties professionally and overcome difficulties that they face, through finding solution.

2) Make efforts to enhance the higher use of technology by teachers of social studies, through encouraging them to participate in activities and socializing their peers, attends clubs to share their ideas, and use research tools to solve problems reasonably besides participation in conferences and debates to enrich capabilities and skills.

3) Activate the utilizing of technological experiments in term of using equipments and programs by the teachers of primary grade.

4) Training programs are necessary for school principals and assistant, with other educational leaders, to clarify the roles and tasks of teachers, so as to improve the teaching-learning process, to achieve the principle of educational integration.

\section{References}

Ajir, R. (2004). How Do Teachers Employ ITT in Explaining the Curricula. Cairo Egypt dar al faroug Publishing and Distribution.

Akahori, K. (2002). Qualitative Analysis of Information Communication Technology Use on Teaching Learning Process. ERIC Document Reproduction Service No. FD 34456509.

Al Jund, A. (2005). Efficiency of Contextual Modulus in Developing the Competencies of Employing the IT by the Teachers of Secondary Grade in Saudi Arabia, University of Umm ALqura. Journal of Education, 17, 70-121.

Al Salimi, A. (2010). Information Technology. Amman: Dar Almanahij (P and D).

Al Sharhan, J. (2002). Study of the Perspectives of Academics of Faculty of Education of University of King Saud on the Internet. Journal of King Saud University, 2, 551-572.

Alattal, B. (2009). The Use of Eduwave by Teachers of Amman Education Directorate and Their Attitudes towards It. Unpublished Master Thesis, Amman: University of Jordan.

Albalaw, M. (2010). Obstacles against the Use of Technology in Education, as Perceived by the Teacher of Arabic Language in the Saudi Public School Tabuk. Master Thesis, Faculty of Graduate Studies, Amman: University of Jordan.

ALdhoon, M. (2008). The Using of E-Learning System as Perceived by the Teachers in Jordan. Unpublished Master Thesis, Yarmouk: Yarmouk University.

Alghamedi, S. (2005). The Use of Computer by the Counselors in the Secondary Schools of Riyadh. The 12th Conference on the Psychological Counseling for Development, 1, 715-756.

Alhaqiqah Aldawliah Liddirasat (Alhaqiqa for Studies) (2009). Development of Education Sector: Accomplishments of Jordan during Independence. 
https://scholar.google.com/schola

Alhazzani, N. (2008). The Use of Computer and IT in the Secondary Schools of Riyadh as Perceived by Female Teachers and Students. Journal of Social and Educational Studies, 15, 107-136.

Alhusari, K. (2014). The Impact of Using E-Learning Environment Based on Web 0.2 Applications in Developing the Cognitive Aspects and Some Skills by the Students of Social Studies Department. Journal of Educational Society for Social Studies, No. 56, 15-39.

Almekhlafi, H. (2011). A Proposed Program for Developing the Skills of IT by Students of Ta'az University and Its Impact on Their Attitudes towards Self Learning. Unpublished Doctorate Dissertation, Educational Studies Institute, Cairo: Cairo University.

Almousa, A. (2002). Using IT and Computer in the Primary Grade in the Gulf State. A Field Study. Riyadh: Office of Gulf State Education.

Alomari; A., \& Alomari, K. (2008). Employing the Information Technology and Telecom in the Skills of Class Teaching Situation in the First Three Grades in Irbid as Perceived by Teachers. Journal of Tashreen University, 30, 1.

Alshiri, M. A. (2005). The Role of Teacher in the Age of informatics. Journal of Libraries and Information, 25, 4.

Alzaboon, M., \& Ababneh, M. (2010). Future Perceptions for Using ITT in Developing the Educational System. Journal of Alnajah University, 24, 800-826.

Banat, S., Gaith, S. M., ALbana, M., \& Albadareen, G. (2013). Applying the Computer Techniques by the Teachers of Social Studies in the Public Schools in Jordan. Journal of Education, 28.

Cohn, E., \& Geske, T. (1990). Ch. 7: Production \& Cost Functions in Education. In The Economics of Education (pp. 159-210). New York: The Free Press.

Eissan, S., \& Ala ni, W. (2008). The Role of IT in Managing Knowledge at the Faculty of Education in Sultan Qaboos University. Journal AL basa'ir, 12, 59-84.

Fisher, H. E., Aron, A., \& Brown, L. L. (2006). Romantic Love: A Mammalian Brain System for Mate Choice. Philosophical Transactions of the Royal Society: Biological Sciences, 361, 2173-2186. https://doi.org/10.1098/rstb.2006.1938

Grudin, J. (1990). The Computer Reaches Out: The Historical Continuity of Interface Design. In Proceedings of the SIGCHI Conference on Human Factors in Computing Systems: Empowering People (pp. 261-268). New York: ACM Press.

https://doi.org/10.1145/97243.97284

Gusnard, D. A., Akbudak, E., Shulman, G. L., \& Raichle, M. E. (2001). Medial Prefrontal Cortex and Self-Referential Mental Activity: Relation to a Default Mode of Brain Function. Proceedings of the National Academy of Sciences of the United States of America, 98, 4259-4264. https://doi.org/10.1073/pnas.071043098

Hathanwi, W. N. (2009). The Role of Informatics in Developing the Vocational Performance of Teachers of the Vocational Schools in Palestine as Perceived by Principals and Teachers. Unpublished Master Thesis, Palestine: Alnajah University.

Helfer, M. E., Keme, R. S., \& Drugman, R. D. (1997). The Battered Child (5th ed.). Chicago, IL: University of Chicago Press.

Hinnawi, M., \& Helmi, M. R. (2003). Attitudes of Academic Supervisors towards the Uses of Internet in Education at Open Alqods University. Unpublished Master Thesis.

Judah, A. (2004). Obstacles against Using the Internet by Teachers and Students, and Their Attitudes towards It in Teaching the Social Studies of the Secondary Grade. Studies in Curricula and Teaching Methods No. 96. 
Karmah, M. (2010). The Extent of Consistency of Teacher Competency and Technological Education as Perceived by the Principals and the Criterion of Competency for the Teacher. Unpublished Master Thesis, Palestine: University of ALnajah.

Khoza'a, T., Al Hirish, A., \& Jawarneh, T. (2006). The Extent of Possession of Computer Skills and Their Level of Practice. Journal of Educational Sciences, 8, 44-71.

Khreishah, A. K. (2011). The Status of Using Computer and Internet by the Teachers of Social Studies in Jordan. Journal of Damascus University, 2, 653-688.

Lieberman, A. F., \& Amaya-Jackson, L. (2005). Reciprocal Influences of Attachment and Trauma: Using a Dual Lens in the Assessment and Treatment in Infants, Toddlers, and Preschoolers. In L. Berlin, Y. Ziv, L. Amaya-Jackson, \& M. T. Greenberg (Eds.), Enhancing Early Attachments: Theory, Research, Intervention, and Policy (pp. 120-126). New York: Guilford Press.

McAndrew, P., Clow, D., Tylor, J., \& Aczel, J. (2004). The Educational Design of a Knowledge Network to support Knowledge Management and Sharing for Lifelong Learning. British Journal of Educational Technology, 35, 739-746. https://doi.org/10.1111/j.1467-8535.2004.00431.x

McCoy, C. (2005). A Examination of Urban Suburban School Counselors' Familiarity with and Usage of Computer Technology. Journal of Technology in Counseling, 4, 220-312. https://www.google.jo/?gfe_rd=cr\&ei=xyO0WLzBJ6is8wegpajIDg\#q

Othman, A. (2004). Technology and the School of Future: The Presence and Future. A Paper Presented to the Seminar of Future Schools, Riyadh, Saudi Arabia.

Packard, N., \& Rais, F. (2003). Employing Information Technology in the School. Cairo: Dept. of Educational Studies.

Philip, H. (1988). The Measurement of Service Quality: A New P-C-P Attributes. International Journal of Quality and Reliability Management, 14, 260-286.

Qandeelji, A. (2010). The ITT Dictionary. Amman: Dar ALmanahij.

Rawathiah, S., Hasan, B., \& Omar, O. (2011). Technology and Design of Teaching. Amman: Zamzam (P and D).

Schnase, J. L., \& Cunnius, E. L. (1995). Proceedings from CSCL'95: The First International Conference on Computer Support for Collaborative Learning. Mahwah, NJ: Erlbaum. https://doi.org/10.3115/222020

Stasious, P. E., \& Angeli, C. (2008). Evaluating the Use of ICT in Education: Psychometric Properties of the Survey the of Factors Affecting Teachers Teaching with Technology (SFA-T3). Educational Technology \& Society, 11, 69-86.

Steven, P. (2007). Training Rural Special Educators Online to Teach Social Skills. Rural Special Education Quarterly, 26, 16-20.

Walton, T., \& Linda, B. (2006) Information Technology Teachers' Perception of Implementing the National Education Technology Standards. PhDDissertation, Fort Collins, CO: Colorado State University.

Zeighan, A., \& Alkhateeb, A. (2009). Knowledge Management and Information Systems. Irbid: Jadara for Textbook (P and D). 
Submit or recommend next manuscript to SCIRP and we will provide best service for you:

Accepting pre-submission inquiries through Email, Facebook, LinkedIn, Twitter, etc. A wide selection of journals (inclusive of 9 subjects, more than 200 journals)

Providing 24-hour high-quality service

User-friendly online submission system

Fair and swift peer-review system

Efficient typesetting and proofreading procedure

Display of the result of downloads and visits, as well as the number of cited articles Maximum dissemination of your research work

Submit your manuscript at: http://papersubmission.scirp.org/

Or contact ce@scirp.org 